\title{
The application of Educational Psychology in Higher Vocational Education work
}

\author{
Huayao $\mathrm{Xu}$ \\ Handan Polytechnic College \\ Handan,056001, China
}

\begin{abstract}
Higher Vocational Education is a special higher education, training practical talents for our country, offering the most generous and solid support to enhance the competitiveness of our country and making a contribution to China's economic development. With the rapid development of social economy, our life has been changed day by day, of course, pressure from various aspects is also growing. However, more and more only-child lack of mental capacity, prevalently have psychological defects or psychological block because of their parents and grandparents' dotage .The application of positive psychological ideas to improve college students' mental capacity, and develop their excellent quality ,are significant for enhancing the effectiveness of higher vocational education management and comprehensively promoting the healthy development of vocational students.
\end{abstract}

Keywords- positive psychology; Higher Vocational Education; Education Management

\section{INTRODUCTION}

In recent years, with China's rapid development of Higher Vocational and Technical Education, and the increasing number of higher vocational students, the Vocational Education has become an important part of higher education. The higher vocational educations' open teaching environment ,rich teaching content, diverse teaching methods and frequent interpersonal communication in teaching determine its irreplaceable advantages in training mental health and quality of students. Faced with the huge group of vocational students, how to improve their subjective well-being, which has been an important issue placed in front of the educators .Positive psychology is a new field of research raised in the end of 20th century ,which advocated positive orientation of psychology research, concerned about human positive psychological quality, emphasized on human values and human care, interpreted Psychology with a new attitude.

\section{HIGHER VOCATIONAL STUDENT' COMMON} PSYCHOLOGICAL PROBLEMS AND THEIR PERFORMANCES

\section{A. Individual psychological problems}

Vocational students who are in the period of youth, experienced a frustration in academic, and have a relatively common mentality such as "the absence", "the loser", "the superfluous man", and think that he is a man without achievement in the future, or can not contribute much in career, have no hope for future, therefore, they often perform as spiritual malaise, making no progress in ideology, no progress in learning, slack in life. Lack of positive ideals and the pursuit ,weak in social adaptation, make it difficult for them to have a healthy personality and uplifting character .

\section{B. Self psychological problems}

A considerable part of vocational students lack of reasonable self-awareness, improper self-evaluation, and have glaring contradictions between ideal self and actual self, between subjective self and objective self.

On the one hand, They perform to be arrogance impetuous. They have lofty ideals, but refused to do solid work and accumulate, ambitious ,always want to reach for what is beyond their grasp ,and their utilitarian mentality is strong. On the other hand, they perform to be inferiority cowardice. They Underestimate their ability and potential, always feel inferior to others, afraid of "thinking, saying and doing," fear psychological stress caused by failures ,weak in frustrative tolerance .

\section{Interpersonal psychological problems}

Some vocational students are difficult to obtain satisfaction in real interactions, they indulge in network communication , and try to get compensation in the online world, which result in shrinking interpersonal emotions, making relationships more apathy, resulting in severe interpersonal psychological disorder .They are in such Psychological states: indifferent, that is ruthless; lack of energy, that is weakness; unconcerned, that is careless. In addition, with the awakening of Sexual consciousness, vocational students have gradually passed an alienated period of alienating the heterosexual, and have gone into the period of approaching the opposite sex ,they desire to establish a good relationship with the opposite sex, but not sensible to treat their hazy feelings, which triggered vocational students' psychological problems and moral fault of sexual behaviors are quite common.

\section{MAKE THE POSITIVE PSYCHOLOGY FULLY PLAY A ROLE IN STUDENT EDUCATION MANAGEMENT}

Vocational students is a group which can not be ignored and discounted, which should be dynamic, vibrantly young groups, and must be a force of social development and progress for the future of constructing the urban and rural in the future. Staying in school is a transition period of vocational students' mental maturity , and the best period of their personality tends to be shaped, but also the best and critical time for them to receiving psychological education. Vocational colleges should attach great importance to 
psychological education, scientific implementation , actively exploration, the overall promotion, concentrate on the implementation, enhance the level, create characteristics, and strive to open up a new realm of psychological education, carry out the quality of vocational colleges education in practice.

The first is to help students to establish correct moral values. With rapid economic development in present society, some vocational students are disoriented, money worship, individualism, pragmatism and other distorted values erode their minds, which make them have improper moral values. Positive Psychology advocates to stimulate students' positive qualities, and make them have noble characters, therefore educators can not blindly have a ideological indoctrination to students, they should be adept at the using facts and attitudes to slowly affect the students, timely guided on issues that students concerned, timely help students analyze the distortions and immoral things happened in present society, clarify students 'moral doubts, firm positive energy in society and carry forward, make efforts to improve students' moral judgment.

Second, we should strive to develop students' sense of justice and responsibility. Everyone should be in the pursuit of their own rights while actively fulfill their obligations, the majority of educators should actively and correctly guide students to serve others, and serve for the collective, and experience the joy of serving others, feel the happiness in the process of serving others and the community, developing a positive emotion. Cultivating college students a sense of justice, not only needs the constantly improvement of the social system, but also needs students' recognition for the school management system and training system, and then cultivate the students' sense of justice.

Inspire all students' learning motivation. Firstly, the incentive is one of the best ways to improve student learning motivation. Because vocational students have prevalence of learning helplessness orientation or behaviors, and lack of confidence in study before going to college, waking up students' confidence is quite crucial for their study in vocational stage.

Right incentives can enable students to get a sense of accomplishment, and enhance their self-confidence, thereby enhance students' motivation. Secondly, psychological research shows that a variety of feedback information from the study results, have a significant impact on learning effects. In the teaching process, teachers should combine with motivational strategies, and at the same time , have correct, positive evaluations on students, students can adjust the learning activities based on the feedback information to improve learning strategies;

Meanwhile, in order to achieve better results or to avoid further mistakes they enhance learning motivation, thereby they maintain learning initiative and enthusiasm, change teachers' external "pull" into students' inherent "push."

Learning migration strategy: use migration laws, and improve teaching effectiveness. Firstly, teachers should be familiar with textbooks, and mastering the textbooks' structure, creating problem situations, and implementing heuristic teaching. Among the factors which affect migration ,the more similar factors, the greater the possibility of learning migration can be made, and therefore constructivist specially emphasis on the authenticity of learning. In practical teaching, vocational teachers should be based on the characteristics of classes to innovative teaching mode, try to create the problem situation, and implement heuristic teaching. Teachers introduce the contact of new and old materials, reasonably master and make use of the appropriate existing span between new knowledge and students, design appropriately difficult problems, create problem situations, let students have the initiative, increase the possibility of migration generation.

\section{HighER EDUCATION THEORIES IN HigHER VOCATIONAL TEACHING}

Students management regulations, collective goals of class, class collective opinions and group norms of class constitute of collective power systems of class. Under the norms and collective power system pressure, students often exhibit herding, obedience and other social psychological phenomena, such as compliance with studying and resting system, get up in the morning on time, tidy up the room, do morning exercises and so on. Such conformity and obedience occurred under the pressure of specification and groups, and it's just compromises that made for not willing to be a collective rejection or individual sanctions make compromises, is not real change of voluntarily actions and attitudes. Therefore, the use of dynamic class management mechanism should not only satisfied with this, we should pay attention to make use of the power of the example to promote student perform a social psychological phenomena of imitating the identified example, so as to make class management to obtain qualitative improvement.

Therefore, setting the progressive students in the class as an example ,is an important method to encourage students to imitate and have identified behaviors.

For young students, imitation appears on the basis of social cognition, which occur entirely voluntarily; recognition is further than imitation, including consistent cognition, emotion and behaviors, therefore it has more positive sense to promote students consciously, initiatively study from the model. Use social psychological dynamic mechanism to manage classes, teachers should strengthen the positive behavior of students in time, and encourage the positive behavior frequently appear and then internalize into the student's own personality characteristics.

\section{THE IMPORTANCE OF EDUCATIONAL PSYCHOLOGY ON STUDENTS TEACHING WORK}

Firstly, developing educational psychology in students teaching job contribute to strengthening and improving the work of the students' Psychological Counseling ,nowadays the rapid development of society, economic development, many outside factors have a certain impact on students' psychology, when teachers teach students, they should adapt to the times , and use the educational psychology to pay attention to student mental state and mental outlook, which is more powerful to carry out the work of psychological 
education for students. Secondly, implicating educational psychology in student teaching work, is also helpful for teachers carrying out scientific work of students management. Reasonably systematic use of educational psychology, can allow teachers to be more systematic, more generalized, more structurally carry out students management, making students' education management to achieve better results.

Finally, educational psychology applied to students education can do help to strengthen the target and predictability of students' psychological education ,educational application psychology can help teachers understand the students' psychological needs, understand the students' psychological motivations, think of students' purposes and future behaviors, psychological education on signs, and eliminate all bad, adverse psychological behaviors, ensure the healthy development of students.

\section{A. Focus on the emotional education in education and teaching students}

The so-called emotional education is to make students feel better about themselves, in teaching students, focusing on the emotional education, will help to enhance the educational results. Therefore, students in accepting the demands and views of teachers must be accompanied with the teachers' care and love, students only really feel the teachers' care and concern do they have a trust on teachers, and listen to the opinions of teachers, strive to complete the teacher's requests .If students do not feel teachers' love, for the same demands and views, students often have psychological conflict, resist these demands. Therefore, caring them is the foundation of emotional education of students, but also the basis to communicate with students .Only pay truly sincere and selfless love to students, can we win the respect and trust of students, so as to establish a good relationship between teachers and students, and make students listen to the advice of teachers and meet the requirements of teachers, so that students can learn and grow in a better life .

\section{B. Communicate with students in the soul}

When students tell their teachers or counselors their distress and negative emotions in their life, the teacher will play the role as psychotherapist. Firstly, listen carefully to the students about their troubles, so that students can put down all their burdens here, then according to the characteristics of their problems and solve the problems one by one. In fact, teachers often only need to listen patiently, students say out all their troubles, the basic problems have been solved half, then you need proper guidance of teachers enlightening process. Therefore, as a qualified teacher a new era must be patiently listen to the students' troubles and problems.

Effectively and reasonably implicating emotional education can be said that ,the word "emotional education" in the basic definition by Western scholars, which generally refers to people's react to objective things. It is generated in people's daily life. Generally speaking, emotional education is that students can receive a pleasant, happy education. Therefore, in the education work of teachers or counselors, using emotional education plays a pivotal role in improving teaching efficiency. In the education and teaching work of students, the emotional education is a kind of ideological transformation, a certain kind of teacher requests and comments, students only really have a sense of trust in the teacher, will he identify and accept with the recommendations and requirements of the teacher. Conversely, if students believe the behaviors and suggestions of teachers or counselors are not real concerns for them, the students will have not accepted in their behaviors. Therefore, only teachers or counselors show their heartfelt concern, teachers fully apply the emotions to educate their students, especially for relatively backward students in learning and ideology, so that they can personally feel the love from a teacher or counselors' warmness, they will gradually eliminate antagonism to the teacher or counselor, at the same time, it is easier for educators to help them have a progress in study and ideology.

\section{CONCLUSIONS}

The educators who have long been engaged in the student's education will more or less use some theoretical related to educational psychology, an excellent teacher is first and foremost a good psychologist. Moreover, what can not be ignored is that in the current teaching process, there are a lot of workers not well paying attention to this aspect, including some teachers with very prominent teaching capabilities ,teachers who can take the initiative to spend time, efforts and energy in researching in educational psychology to apply to the teaching practice is still a small part. In order to achieve teaching objectives, most of the teachers will concentrate on areas of expertise in-depth to study or think, hoping to improve their professional capacity to have a good teaching, which is worth encouraging . Only having an in-depth understanding of educational psychology, a clear understanding of the stages of student psychology and character, and making appropriate education adjustments, can truly achieve the goal of education.

\section{References}

[1] Wang Yan The application of Educational Psychology in student teaching work [J] modern communication, 2011,09: 197-198.

[2] Peng Songlin The application of Educational Psychology in student teaching work [J] reading abstracts, 2014,18: 111.

[3] Zhou Jun The application of Educational Psychology in the student's education work $[\mathrm{J}]$ today Southland (theoretical innovation Edition), Jan. 2009: $69+73$.

[4] Wang Jing A brief analysis on Educational Psychology in Higher Vocational Teaching [J] occupation space, 2009,06: 52.

[5] Wang Jiali The application of positive psychology students in vocational education management [J] Technology Information, 2012,34: 192.

[6] Li Jun Higher Educational Psychology in the ideological and political education in vocational colleges - Take the student ethics teaching as an example [J] age education, 2013,07: 200-201. 